\title{
Not So Good Vibrations: Vascular Reflux and the Sensation of Retropubic Vibration following Nova sure Endometrial Ablation
}

\author{
Anouk Benseler ${ }^{1}$, Ben Mussari ${ }^{1,2}$, Robert Reid ${ }^{1,3}$ and Romy Nitsch ${ }^{1,3 *}$ \\ ${ }^{1}$ Queen's University School of Medicine, Canada \\ ${ }^{2}$ Department of Diagnositic Radiology, Queen's University, Canada \\ ${ }^{3}$ Department of Obstetrics and Gynaecology, Queen's University, Canada
}

Submission: March 03, 2017 ; Published: March 23, 2017

*Corresponding author: Romy Nitsch MD MHSc, Department of Obstetrics and Gynaecology, Queen's University, Kingston General Hospital, 76 Stuart Street, Kingston ON, Canada, Email: Romy.nitsch@queensu.ca

\section{Abstract}

Background: One in five women suffer from abnormal uterine bleeding and endometrial ablation often successfully treats refractory abnormal uterine bleeding. The second-generation Nova Sure endometrial ablation system is effective and safe. We report a case of vascular reflux from ovarian vessels creating a retropubic vibration after Nova Sure endometrial ablation.

Case: A 48-year-old woman with an endometrial ablation six months previously presented with a confusing complaint of retropubic vibration that had been dismissed by several physicians as impossible to explain. Investigation revealed left ovarian varicosities and an aberrant vessel behind the pubic symphysis that coursed from the left uterine venous sinus into the right internal iliac vein.

Conclusion: This case report presents an unusual postoperative complication of endometrial ablation and reinforces the need to carefully evaluate patient complaints even when they may seem contrived.

Keywords: Endometrial ablation; Nova sure; Vascular reflux; Ovarian varicosities; Aberrant vessel

Abbreviations: AUB: Abnormal Uterine Bleeding

\section{Introduction}

One in five women suffer from abnormal uterine bleeding (AUB) [1]. Endometrial ablation is minimally invasive surgery designed to treat AUB refractory to medical management [2-5]. Endometrial ablation destroys or removes the endometrial lining of the uterus with the aim to decrease or eliminate menorrhagia, and increase quality of life in women who do not desire to be fertile in the future [2]. In the past 20 years, non-resectoscopic second-generation endometrial ablation techniques have been developed to shorten operative time, minimize complications and reduce the amount of operative equipment required [6,7].

The NovaSure endometrial ablation system is a nonresectoscopic second-generation single-use device which utilizes bipolar radiofrequency energy [2]. Its application is a wellestablished safe procedure with only rare serious complications $[2,8]$. Cardiovascular complications noted in the literature include hypotension, chest pain, deep vein thrombosis, CO2 embolism, bradycardia, pulmonary embolism, and cardiac arrest [7,9]. We describe an unusual case of vascular malformation specifically venous reflux following Nova Sure endometrial ablation which has to date not been noted (Figure 1).

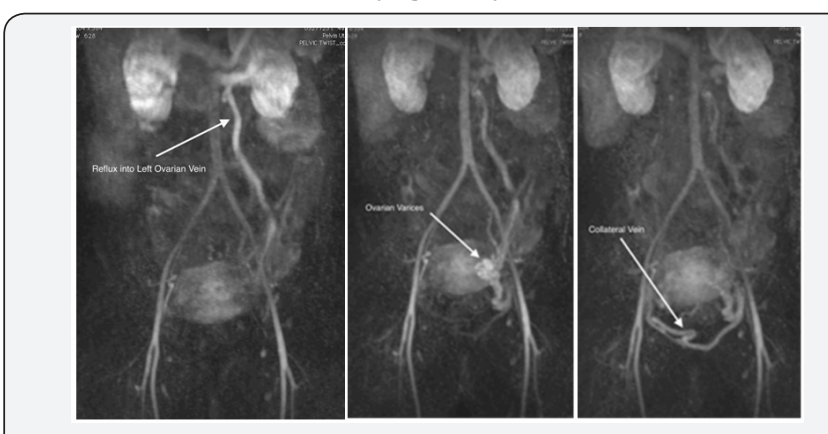

Figure 1: Time resolved magnetic resonance angiogram demonstrating the reflux pathway from the left renal vein via (a) the left ovarian vein, through (b) multiple pelvic/left ovarian veins and varicosities, into (c) a large aberrant collateral vein. 


\section{The Case}

A 48-year-old multiparous woman presents with a five-year history of uterine bleeding. After no improvement of menorrhagia was found with medical therapies including oral tranexamic acid (Cyklokapron $®$ ), and the Mirena IUS failed to control bleeding, a decision was made to proceed to endometrial ablation. A week prior to the ablation on examination, normal vulva, vagina and cervix were visualized, a PAP smear was performed and a bimanual exam revealed a non-tender abdomen with a small anteverted uterus. There was no mass palpated (Figure 2).

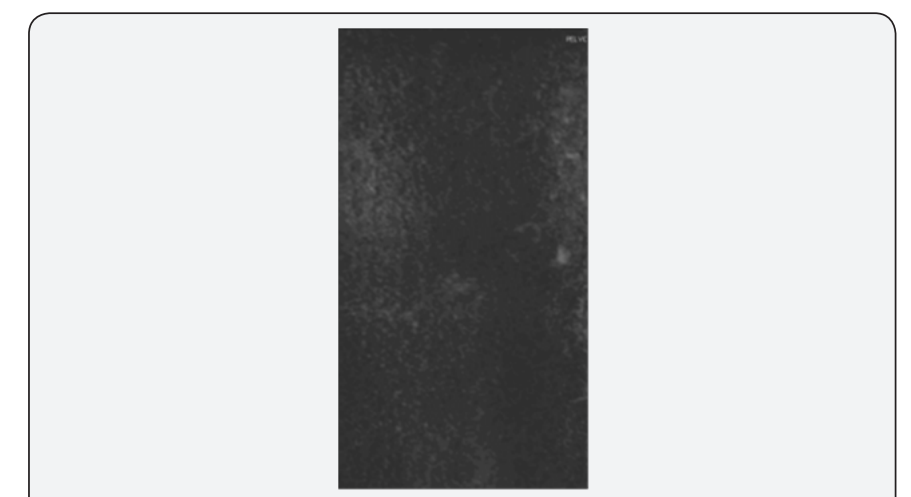

Figure 2: Time resolved magnetic resonance angiogram video of the pathway of retrograde flow.

Under general anesthesia, dilation and curettage was performed. No hyperplasia or malignancy was found. Nova Sure endometrial ablation was then performed as per protocol. The patient's endometrial cavity seemed normal. No intraoperative complications were noted and the patient tolerated the procedure well.

After the ablation the patient's bleeding subsided. Six months after the procedure the patient became aware of a constant vibrating sensation in the retropubic and pelvic region extending down into the vaginal region. The sensation could not be palpated. The patient denied the typical pelvic congestion syndrome symptoms, however the patient did describe aheaviness in the pelvis following exercise and later in the day which resolved in the recumbent position. Apart from the vibration sensation the patient had no other complaints.

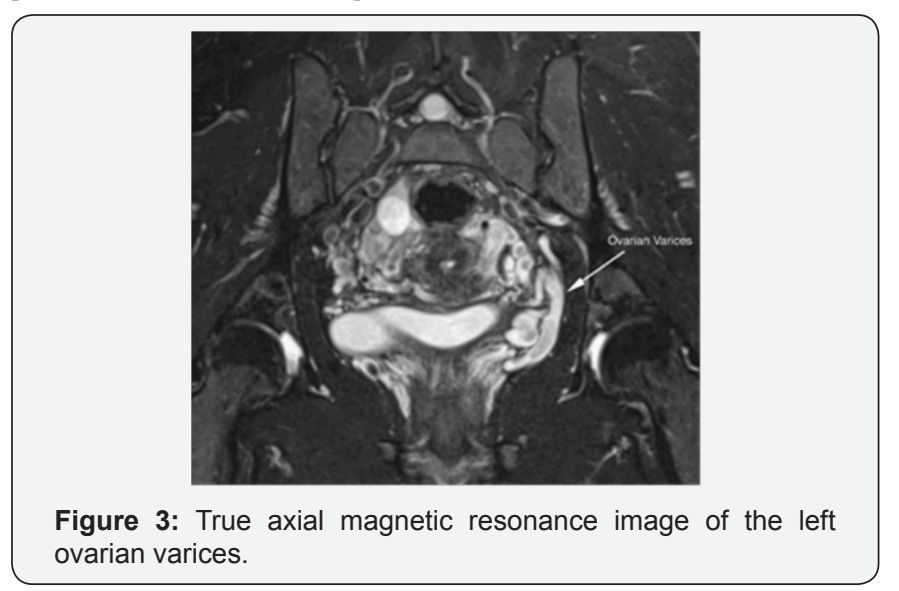

She was evaluated by her family physician and by two different gynecologists. None of these physicians could detect a vibration nor could they explain the cause of the symptom. Considering that an arterio-venous fistula is often associated with vibration one of the physicians recommended a pelvic MRI (Figure 3).

Thirteen months post procedure she was evaluated by diagnostic radiology. Multi planar and multi sequence images including a time resolved MR angiogram of the abdomen and pelvis showed left ovarian varicosities and dramatic reflux from the left renal vein into multiple pelvic/left ovarian veins all emptying into a large venous sinus at the border of the uterus. The venous sinus appeared to drain through a $6 \mathrm{~mm}$ aberrant retropubic vein across to the opposite side of the pelvis and into the right internal iliac venous system, running in parallel and close contact with the pubic rami. No definite venous outflow via the left internal iliac system was seen (Figure 4).

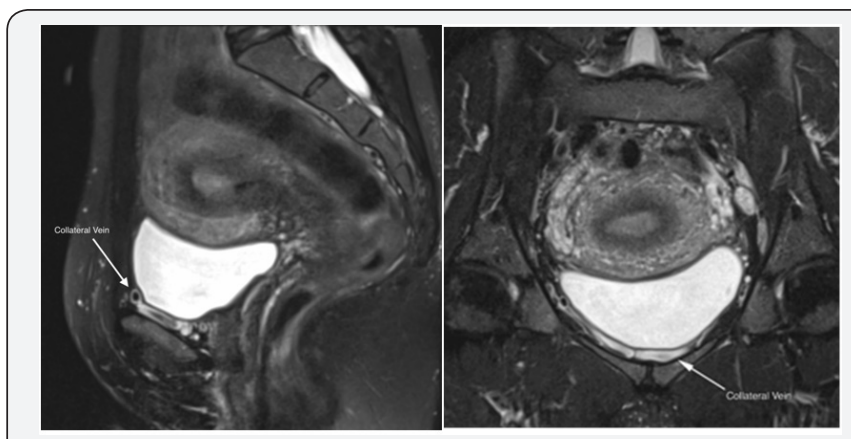

Figure 4: (A) Sagittal anatomic magnetic resonance image of the approximately $6 \mathrm{~mm}$ aberrant vessel behind the pubis symphysis. (B) True axial magnetic resonance image of the same aberrant vessel connecting the left ovarian and pelvic vein plexus with the right internal iliac vein plexus

\section{Discussion}

We performed searches of the electronic database PubMed and the Manufacturer and User Facility Device Experience (MAUDE) database of the American Food and Drug Administration for reports of similar squeal of endometrial ablation and concluded that this is the first report of both ovarian reflux and the subjective sensation of vibration following Nova Sure endometrial ablation.

Ovarian reflux is retrograde flow in the ovarian vein(s) thought to be caused by venous incompetence. In time, it is believed that this retrograde flow then incites the development of varicosities and dilation of ovarian, paraovarian and pelvic veins [10].

The physical symptom of vibration has long been associated with vascular malformations and so the sensory symptom of pelvic vibration occurring in concert with a pelvic vascular malformation may thus be explained [11].

The second-generation NovaSure endometrial ablation system uses thermal energy to vaporize the endometrial wall 
[12]. Under local or general anesthesia, the NovaSure travels the endocervical canal, suctions the endometrium to its triangular conformable mesh head and treats the tissue with a uterinesize appropriated voltage until the tissue impedance increases rapidly indicating the myometrial layer is reached or a maximum time of 120 seconds has elapsed $[4,13]$. As performed without direct visual guidance, the greatest concern of this procedure is off target thermal injury [12].

The NovaSure system assesses cavity integrity pretreatment by $\mathrm{CO} 2$ pressurization to avoid direct off target thermal injury however indirect off target thermal injury may be occurring [4].

Ovarian vein reflux has been reported secondary to a previous pelvic surgery and can arise secondary to a more central flow obstruction [14]. Though its pathology is unknown, it is thought to result from a combination of dysfunctional venous valves, retrograde blood flow and venous engorgement [15]. Venous valves may be physiologically absent in the cranial portion of the ovarian vein in up to $15 \%$ of women on the left side and in up to $6 \%$ on the right side, and valvular incompetence may be found on at least one side in almost $50 \%$ of women [16].

The ovarian veins arise from the ovarian vein plexus which has venous communication with the uterine plexus [17]. Thermal propagation or mechanical damage causing reflux and engorgement could thus originate in the uterine or ovarian vein plexus or impact the ovarian vein or one of its draining vessels.

The injury in this case likely affected a greater draining vessel as no definite venous outflow via the left internal iliac system was seen. Reflux from the left renal vein drained into multiple left ovarian veins and pelvic veins. All venous out flow appeared to eventually flow through an enlarged congenitally aberrant retropubic vein to the right iliac venous system.

The retropubic path of this aberrant vein parallel to, and in close contact with, the pubic rami, and its size of $6 \mathrm{~mm}$ may explain the patient's vivid pelvic vibration. The patient's history, examination and other investigations offered no alternate explanation therefore vascular embolization of the enlarged vein and the left ovarian vein was recommended [18,19].

The patient had consultation with radiology but was fearful of having a coil placed and at present has decided to tolerate the sensation. The conclusion that the endometrial ablation precipitated the pelvic vibration in this case is limited by the lack of any vascular investigations of the pelvis prior to the procedure and our inability to date to confirm the association between the vascular malformation detected and the vibration sensation. This later concern will be obviated if embolization resolves the complaint.

A second opinion sought by the patient could find no crossmidline filling of pelvic varices, no significant pelvis abnormality and no cause for her vibration.
It was noted that the left ovarian vein was moderately enlarged leading to left-sided pelvic varices and the uterine arteries were mildly enlarged and hypervascular. No arteriovenous malformation or fistula was perceived.

\section{Conclusion}

This case report is the first to describe vascular malformation, specifically ovarian reflux, and a subjective report of a sensation of pelvic vibration following second-generation Nova Sure endometrial ablation. The vascular malformation was most likely pre existing however the time course of events suggests that increased vascular flow diverted into the vessel following endometrial ablation may have precipitated the noticeable vibration. Endometrial ablation is generally a safe and well tolerated procedure. This unusual complication reminds us that interventions that impact pelvic blood flow can have unintended consequences.

\section{Acknowledgement}

The woman whose story is told in this case has provided written consent for its publication.

\section{References}

1. Lethaby A, Penninx J, Hickey M, Garry R, Marjoribanks J (2013) Endometrial resection and ablation techniques for heavymenstrual bleeding. Cochrane Database Syst Rev 8: CD001501.

2. Laberge P, Leyland N, Murji A, Fortin C, Martyn P, et al. (2015) Endometrial ablation in the management of abnormal uterine bleeding. J Obstet Gynaecol Can 37(4): 362-376.

3. Fakih M, Cherfan V, Abdallah E (2011) Success rate, quality of life, and descriptive analysis after generalized endometrial ablation in an obese population. Int J Gynaecol Obstet 113(2): 120-123.

4. Gimpelson RJ (2014) Ten-year literature review of global endometrial ablation with the Nova Sure(R) device. Int J Womens Health 6: 269280 .

5. Fulop T, Rakoczi I, Barna I (2007) Nova Sure impedance controlled endometrial ablation: long-term follow-up results. J Minim Invasive Gynecol 14(1): 85-90.

6. Fergusson RJ, Lethaby A, Shepperd S, Farquhar C (2013) Endometrial resection and ablation versus hysterectomy for heavy menstrual bleeding. Cochrane Database of Systematic Reviews 11: CD000329.

7. Badia DC, Nyirjesy P, Atogho A (2007) Endometrial ablation devices: review of a manufacturer and user facility device experience database. J Minim Invasive Gynecol 14(4): 436-441.

8. Gurtcheff SE, Sharp HT (2003) Complications associated with global endometrial ablation: the utility of the MAUDE database. Obstetrics \& Gynecology 102(6): 1278-1282.

9. Overton C, Hargreaves J, Maresh M (1997) A national survey of the complications of endometrial destruction for menstrual disorders: the MISTLETOE study. Minimally Invasive Surgical Techniques--Laser, EndoThermal or Endorescetion. Br J Obstet Gynaecol 104(12): 13511359.

10. Cura M, Cura A (2009) What is the significance of ovarian vein reflux detected by computed tomography in patients with pelvic pain? Clin Imaging 33(4): 306-310. 
11. Aoki T, Shinzato T, Itani H, Kato T, Miwa M, et al. (1996) Advantage of monitoring skin vibration as an index of arteriovenous fistular blood flow. Artif Organs 20(3): 277-279.

12. Brown J, Blank K. (2012) Minimally invasive endometrial ablation device complications and use outside of the manufacturers' instructions. Obstet Gynecol 120(4): 865-870.

13. Bongers MY (2007) Second-generation endometrial ablation treatment: Novasure. Best Pract Res Clin Obstet Gynaecol 21(6): 989 994.

14. Koo S, Fan CM (2014) Pelvic congestion syndrome and pelvic varicosities. Tech Vasc Interv Radiol 17(2): 90-95.

15. Phillips D, Deipolyi AR, Hesketh RL, Midia M, Oklu R (2014) Pelvic congestion syndrome: etiology of pain, diagnosis, and clinical management. J Vasc Interv Radiol 25(5): 725-733.

This work is licensed under Creative

Commons Attribution 4.0 Licens

DOI: 10.19080/JGWH.2017.03.555615
16. Tropeano G, Stasi DC, Amoroso S, Cina A, Scambia G (2008) Ovarian vein incompetence: a potential cause of chronic pelvic pain in women. Eur J Obstet Gynecol Reprod Biol 139(2): 215-221.

17. Kennedy A, Hemingway A (1990) Radiology of ovarian varices. Br J Hosp Med 44(1): 38-43.

18. Leiber LM, Thouveny F, Bouvier A, Labriffe M, Berthier E, et al. (2014) MRI and venographic aspects of pelvic venous insufficiency. Diagnostic and Interventional Imaging 95(11): 1091-1102.

19. Dos Santos SJ, Holdstock JM, Harrison CC, Whiteley MS (2015) Longterm results of transjugular coil embolisation for pelvic vein reflux Results of the abolition of venous reflux at 6-8 years. Phlebology 31(7): 456-462.

\section{Your next submission with Juniper Publishers} will reach you the below assets

- Quality Editorial service

- Swift Peer Review

- Reprints availability

- E-prints Service

- Manuscript Podcast for convenient understanding

- Global attainment for your research

- Manuscript accessibility in different formats ( Pdf, E-pub, Full Text, Audio)

- Unceasing customer service

Track the below URL for one-step submission https://juniperpublishers.com/online-submission.php 